\title{
An Examination of Research Agency and its Practical Applications
}

\author{
Abeni El-Amin ${ }^{1,2}$ \\ ${ }^{1}$ Robbins College of Business and Entrepreneurship, Fort Hays State University, Kansas, United States \\ ${ }^{2}$ College of International Business (CIB), Shenyang Normal University (SNU), Liaoning Province \\ Corresponding author email: aelamin@fhsu.edu \\ Received: 04 September 2021 / Accepted: 23 November 2021 / Published: 05 December 2021

\section{ABSTRACT} \\ The goal of this evaluation is to offer instructive practice on how to improve researcher agency. \\ Indicated are how the literature review is an investigative process providing context to research studies \\ and overall scholarship. Further, practical connection exhibits how exceptional research skills improve \\ the body of information, structure, and quality needed to investigate global issues. Researchers provide \\ a comprehensive analysis of phenomena to convey conceptual, theoretical, and empirical analysis of \\ studies. Further, substantive feedback from collaborative research teams allows for corroboration and \\ a refined final product. Likewise, the content of a research study must align to reflect objectivity and \\ continuity. Conclusively, researchers must employ a regimented and ethical process to refine \\ conceptual, theoretical, empirical, or grey literature studies to provide focus, clarity, and organization.
}

Keywords: Literature Review, Research Quality, Research Agency.

\section{Introduction}

Ethical research requires exploration, reflection, and introspection. Likewise, a comprehensive, structured literature review is essential to improve research agency. Research agency is based on the articulated belief in one's ability to take the initiative required to accept an active role in one's own learning environment, context, process, and engagement (Jääskelä et al., 2021; Rigler et al., 2021). In comparison, research agency is like andragogy, the study of adult education where adults take responsible for their own learning, quality of research, and engagement. Research agency applies to all who embark on research in an intentional, pragmatic, and engaged manner (Makowski, 2021). Further, exploratory research involves researchers examining the objectives, processes, and research studies (Creswell \& Creswell, 2017). To clarify the literature review process, a researcher must decide if they will approach the research from an inductive or deductive angle. A researcher incorporates evidence of reflection, information, expertise, collaboration, structure, and summary into the literature review. Crucial to any literature review, organizing the study pragmatically is vital to ascertain the investigation's results, objectives, and patterns (Haig, 2018).

The current status of research agency as a conceptual model and in practice lacks comprehensive analysis. For instance, Yang et al. (2020) indicated that knowledge acquisition of research agency needs thorough study from a contextualized perspective. Yang et al. (2020) also acknowledged a gap exists in grasping research agency as a conjectural and practice-based standard. Concomitantly, Makowski (2021) sought to fill this gap by addressing how analytical theory of agency (ATA), as a theoretical framework elevates theory building in management practice. As a result, research is detrimental to organizations and management strategy. As a paradigm, research agency embodies intentionality and provides a theory-topractice framework (Makowski, 2021).

Challenges of research agency as an innovative concept, denotes a less researched theoretical construct. For example, proponents of research agency Jäskelä et al. (2020), described essential components of research agency as intentional, focused, and providing meaningful learning (Jääskelä et al., 2021). Further, organizational training and development regards research agency as central to expertise. Conversely, in higher education, research agency is analytically less researched and lacks an articulate 
theoretical structure (Jääskelä et al., 2020). Indeed, analytical tools for students and instructors need improvement in support of learners in research agency development. Finally, the extent aim of this article indicates how constructing exceptional literature reviews improves research agency. Additionally, in application, remarkable research skills advance the body of scholarship and increases expertise in the professions.

\section{The Scientific Method as a Guide}

Most research studies in the social and behavioral sciences utilize the scientific method (Privitera, 2019). Notwithstanding, appropriate examination relies to a great extent on discipline-explicit methods. However, it is feasible for research to be methodical without adjusting the components of the traditional scientific method (Zikmund, 2013). For instance, when ethnographers conduct research studies, they might not have deduced hypotheses, yet numerous aspects of their research use conventional methodology, including the determination of subjects, preferences about perceptions to record, and the screening process. Further, assessing research development, testing procedures, and evaluation provide effective metrics (Knight, 2012).

Research methods and analysis help researchers understand the scientific method, resources, and research method capabilities, as well as the expectations of their audience (Privitera, 2019). Through research methods analysis, researchers obtain scientific evidence, study development, create a research agenda, enhance the sense of responsibility of a researcher, and help improve the core constructs of disciplines. Indeed, the advantages of research lie in the ability of researchers to analyze research from the aspects of the research question, researcher agency, and research development (Zikmund et al., 2013). Researchers analyze various disciplines such as politics, economy, sociology, technology, environment, and law in the social sciences. Through research methods and analysis, the researcher obtains scientific information by collecting data. Research aptitude occurs based on comprehensive and systematic research methods and analysis, which provides direction and a clear course to achieve a research methods objective.

Further, the scientific method is the basis of research exploration and provides the framework on which the study's inductive portion rests. Notwithstanding, the literature review is continuously assessed, altered, and revised as an iterative cycle to connect the information pragmatically. Moreover, researchers connect theory to practice by including recommendations (Creswell \& Creswell, 2017). Significantly, researchers assemble a variety of materials to demonstrate a detailed position dependent on evidence. Eventually, researchers provide expertise in that they examine the literature review by stating their findings.

\section{Qualitative, Quantitative, and Mix-Methods Research Paradigms}

Qualitative and quantitative are two sorts of research to draw. Qualitative, subjective examination advances themes of inquiry and requires evaluation through descriptive exploration (Cypress, 2017). Quantitative or metrically based examination conveys information utilizing numbers and metrics as a characterized way to portray the importance of data of a study, utilizing factual information investigation (Haig, 2018). Finally, mixed-methods studies research is a mix of qualitative and quantitative examination. A reliable examination consists of a mixture of the two kinds of exploration (Turner et al., 2017).

The ideal approach to organizing a research study addresses the analytical approaches reflecting the researcher's capacity and aptitudes based on academic preparation, experience, or both. Indeed, the utilization of Boolean sources provides the tools and methods for attaining relevant articles (Sivarajah et al., 2017). Further, research innovation measures the viability of the survey method. Indeed, literature review exercises are a component of the analytical examination. The literature review is an informative exercise in scholarly fields (Creswell \& Creswell, 2017). To this end, literature review research requires reflection, analytical exploration, investigation, and summary times. Research provides expertise in the professions. 


\section{Developing Research Agency}

The nature of writing a literature review differs from other academic writing because it advances researcher agency. When conducting research, it is important to comprehend the process, which entails a clear purpose of the research objectives, analysis, methods strategies, conclusions, and presentation to improve researcher agency (Creswell \& Creswell, 2017). The literature review helps the author to interpret the research of others and provides a process where the scholar can reflect, assert knowledge, gather information, structure, and present corroborations. Vital to any research is how to organize the research to incorporate outcomes, goals, and standards of the study utilizing scientific methods (Haig, 2018).

Additionally, the literature review provides the context for research studies. Literature reviews are frequently evaluated, reevaluated, and amended as an iterative process to link the research premise to scholarly sources (Tuckman et al., 2012). Likewise, research topics emerge from the literature review in that they correlate to ideas and issues important to the scholar (Creswell \& Creswell, 2017). Correspondingly, the literature review is a compiled collection of sources indicating a logical order based upon evidence or outcomes (Somers et al., 2013). The sources within the literature review should follow a structure to include the author(s), research methodology of the source, findings, and recommendations of each reference.

Moreover, reflective activities are an element of academic research (Eisner, 2017). To this end, literature reviews require periods of reflection. Attributes of reflection doing academic research include ensuring that the research is defined and that the study's objectives conclude. Researchers must examine, analyze, and reflect upon new knowledge acquired through research by applying foundational knowledge to current problems or challenges (Yang et al., 2020). Further, honing research skills provide real value in developing aptitude in the professions.

Defined are reliability and validity. Reliability is a measurement, quantification, or data that has high dependability and accuracy. In a quantitative study, validity determines how a concept is accurately measured. The various kinds of reliability are test-retest reliability, internal reliability, and across different researchers (inter-rater or external reliability) (Privitera, 2019). The different types of validity construct, content, face, and criterion validity (Privitera, 2019). Indeed, it is important to conduct research that is reliable and valid.

Further, reliability and validity provide research ethos for research studies (Creswell \& Creswell, 2017). Moreover, regarding relevance, research is time-based in that the scholar must complete the research in a given time frame. Research is continually evaluated, reevaluated, and is amended as an iterative process to contextualize and increase research quality. Likewise, research topics emerge from the literature review in that they correlate to premises and issues important to the scholar (Creswell \& Creswell, 2017). Likewise, research is a compiled collection of materials that indicate a tangible position based upon evidence or outcomes to conclude. Researchers require skill to complete studies, policies, grants, and reports.

\section{$5 \quad$ Ethical Research}

Behavioral researchers in different disciplines approach experiments from an ethical standpoint by incorporating integrity, morals, and ethics (McLeod, 2017). The landmark behavioral study, Milgram's Obedience to Authority Study, indicates that social and behavioral research risks harm related to emotional and psychological well-being, violations of autonomy and privacy, and reputational damage. Despite having an ethical framework, researchers cannot definitively predict risks of harm and must rely on preemptive analysis and research standards to avoid precarious methodology (Privitera, 2019. Moreover, human subject risk mitigation is important in social and behavioral sciences (Creswell \& Creswell, 2017). Thus, researchers conduct humanitarian studies to benefit all by examining the dynamic issues raised by behavioral research with human subjects and integrating ethics to legal standards (Belmont Report, 1979).

Researchers may use human subjects for research if it is within the standards of the Belmont Report (Belmont Report, 1979). For example, a researcher needs clearance to work with human subjects, yet the perspective of many by which extent to protect human subjects is a critical perspective that has changed (Amiot et al., 2020). Notwithstanding research of human subjects based on intergroup relations, permit 
observations to determine the various ways individuals relate to each other, animals, or the natural universe. Amiot et al. (2020) indicated three measurements by which people relate to the natural universe within behavioral science: fortitude with human subjects, creature pride, and human-creature relationship. To begin with, Amiot et al. (2020) developed dependability as a study construct to expound upon factorial construction and perceptive legitimacy to determine connectedness. While humans have a natural affection for the natural universe, behavioral research is needed to understand human subjects and the natural universe better. There are unmistakable perspectives and practices toward research with human subjects (Amiot et al., 2020).

Further, there is an emerging profession of "ethicist," with an adopted code of ethics and evolving process for evaluating research competency in the professions. There is much deliberation to be made regarding the absolute function of animal research (Sprumont, 2020). What is clear is that as the field of behavioral science transforms to embrace heightened awareness ethics regarding studies, researchers need to balance the need for experimental content and animal rights. Further, Kant's theoretical framework of deontology alludes to the relationship between one's ethical morality and the researcher's commitment to the field (Howe, 2019).

Scholars maintain ethics throughout their academic careers by ensuring compliance with academic standards. Presently, online schools are developing at an amazing rate; however, many scholars truly dread online courses because they do not think they are as rigorous as bricks-and-mortar classrooms (Peterson, 2019). Online classes can be just as rigorous, yet some scholars still have doubts (Peterson, 2019). This perspective is due to a great extent because scholars are bound to be dishonest in online courses. Various investigations indicate dishonesty occurs in online courses. While many students operate with academic integrity, the discernment remains. This insight influences suppositions about online classes and even dishonesty practices in bricks-and-mortar institutions. Thus, academic honesty emerges as a preeminent concern in higher education. Peterson (2019) indicates that scholars are dishonest for a myriad of reasons. Purportedly, online versus in bricks and mortar settings are easier to maintain dishonesty.

Additionally, the ramifications of online dishonesty are lackluster concerning institutional followthrough. Moreover, techniques for reducing academic dishonesty in online classes hinge on an instructor's ability to identify academic dishonesty (Jääskelä et al., 2021; Peterson, 2019). Regardless of the rationale for why scholars cheat, it is dishonest to do so and breaks the moral code of academics.

Broadening, a focus on ethics provides researchers with a fundamental understanding and experience within the field using a structured or approach regarding the ethics code. Ethical codes help researchers build competency and professional acumen. Ethics maintain morals and utilize adaptation skills in various circumstances to achieve organizations' or clinics' goals, objectives, and missions (Tarzian, 2017). Additionally, aligning the value of ethics and professionalism to organizational goals is an emerging need in the execution and success of behavioral science. Those in behavioral science must support future colleagues by implementing ethical training programs, which encourage ethical development. Moreover, enhanced ethical attributes of individuals in behavioral science are a benefit to society and the profession.

Scholar performance requires utilizing good judgment in practice. Judgment is used in decisionmaking processes to decide how best to study, when, and why. Academic integrity provides scholars with the ability to study for theory-to-practice application (Peterson, 2019). Execution of academic integrity requires discipline. Integrity necessitates accepting responsibility for one's study style and understanding of requirements. Applying these skills allows scholars to stay on track, which is important to understand the subject matter truly.

Ethically researchers need to protect the human rights of study participants. Ways to maintain and ensure ethics are to fulfill an Institutional Review Board (IRB) process in the academy or research institute. The IRB ensures study participants complete the informed consent and that researchers secure participants' responses by encrypting or locking their information (Belmont, 1979). The Belmont Report was developed in 1979 to assist researchers in ethical research as it applies to human subjects. It is important to denote scholars, practitioners in academia, and research institutes largely utilize the Belmont Report to standardize 
Abeni El-Amin, Extsv. Rev.; Vol. 1, Issue 1, pp: 7-15, 2021

research and conduct research on human and animal subjects. Further, the essential moral standards are contended to control research on human subjects, which are essential in research. These conditions mitigate potential challenges for informed consent, confidentiality, risk management, and researcher agency.

In the past, some researchers used some "ethically questionable" research techniques. Ethically questionable techniques are never useful despite a researcher's aspiration to complete a study. Ethically questionable techniques led to the code of ethics to create assurances in research processes and protect humans, animals, and the environment by incorporating informed consent, confidentiality, parameters, deception, and withdrawal (Belmont, 1979).

\section{Collaborative Research}

From a strategic perspective, research provides an opportunity for researchers to provide collaborate with other researchers. In doing so, researchers establish a clear framework for crosscollaborative evaluation regarding how participatory experiences impact a professional field (Ferreira et al., 2015). An approach to achieving and sustaining high-quality output; thus, emphasizing inputs (research practices) rather than outputs (quality performance), must be conveyed within the research design (Al-Ali et al., 2017). Further, success factors that lead to greater researcher agency are strategic planning (research design and assessment); performance excellence (performance management); professional development (institutional engagement, research design, collaboration), and adaptation (the ability to adapt to internal/external changes) (Haig, 2018).

\section{Sourcing Techniques and Strategies}

Assessing the number of theoretical vs. empirical sources gathered is a beneficial practice when conducting a research study. Areas of improvement needed to meet source requirements for a research focus determines the number of theoretical, empirical, conceptual, and grey literature sources. Grey literature sources may or may not be a major component of research. Nonetheless, grey literature is materials and research developed by entities external to typical publications or academic publishing channels (Okoroma, 2011). Further, various grey literature publication sources are unpublished reports, government documents, working papers, white papers, and assessments included in a study. While grey literature is useful, most studies contain only peer-reviewed academic sources to validate preliminary suppositions (Okoroma, 2011).

Sourcing techniques and strategies employ critical thinking by determining what, why, and how to ascertain the best keywords for a Boolean search. For instance, if a researcher focuses on organizational performance as a keyword search, the words or phrases organizational performance, organizational behavior, change management, leadership, and communication populate reference information. Notwithstanding, the purpose of a thorough Boolean search is to determine the gap in the literature.

\section{Research Evaluation}

Evaluation can provide a different perspective on research. Moreover, evaluation is a contrast from traditional educational practices in that it helps instructors focus on the improvement of the curriculum instead of simple execution. Additionally, engagement by the learner allows the instructor to link connections made during learning (Jääskelä et al., 2021). Challis (2005) purported that there are challenging issues of implementing evaluation practices. For instance, evaluation is considered an advanced educational method as there are challenges that persist in implementing evaluation. In contrast, a lack of support by higher education institutions concerning the time and resources it takes to properly vet educational research challenges instructional effectiveness (Frye \& Hemmer, 2012).

\subsection{Communication Strategy}

Communication is key in working with others in the evaluative process. Communication is derived from the researcher's ability to communicate and improves the process of evaluation. As a result, communication issues may cause dissonance with stakeholders. Albeit, communication issues are inherent 
in research evaluation, while they may be different from researcher to researcher, efforts to mitigate conflict are necessary (Cypress, 2017). Communication issues occur because the evaluator may not meet often enough, too much, or not ensure the correct stakeholders are at the correct meetings. Additionally, attention should be paid to team building to ensure those evaluating research work well together and understand the structure of communication channels.

Transparent communication in the evaluation process occurs due to working relationships and the research team's culture. Nguyen and Kleiner (2003) indicated that organizational factors that negatively impact the communication process cause issues with those on the research team. Deciding which communication goes to who and when depends upon the communication

strategy, culture differences, and evaluation plan. Therefore, the key to successful communication is to maintain transparency throughout the research process.

Differentiating and assessing evaluative research communication is a strategic management concept, which supports and aligns evaluation endeavors with the short-and long-term goals of the research. Traditionally, evaluation is seen as productive when it meets research goals and objectives. Finally, assessing evaluation and research communication determines how measurements of the research objectives align with stakeholder's vision of the evaluation.

\subsection{Evaluation Through Appreciative Inquiry}

Aligning the value of evaluation to research goals is a persistent need in scholarship. Evaluation through appreciative inquiry aims to expand the application to a holistic perspective of evaluation (Preskill $\&$ Catsambas, 2006). Evaluation through appreciative inquiry involves creating a means for evaluators to connect with the heart and logic, which is an innovative method in evaluation practices. However, the use of the evaluation through appreciative inquiry approach is not a typical evaluation method. On the other hand, Evaluation through Appreciative Inquiry effectively supports the need to provide variety in executing evaluation processes by assessing objectives using matrices.

Additionally, this approach offers a specific set of critical and reflective evaluation measures that address alignment between educational and organizational objectives. Appreciative inquiry makes those evaluated less anxious when going through the process. At least participants know the evaluators intend to focus on strengths, closing gaps. Appreciative inquiry forces us to embrace the best of ourselves when we design research or a participant in the evaluation. For instance, instead of concentrating on the negative, which typically is short-sighted, researchers can ponder the why, how it made us feel, and think of ways to improve gaps if there are any.

According to Kellogg (2017), research evaluation highlights the success of new strategies, initiatives, and research. Evaluation outcomes strengthen ongoing strategy development and programming to measure the extent of change. Evaluation undergirds an organization's effectiveness, enhances its ability to develop and efficiently procure new resources. Evaluation adapted to the contexts of a program permits alignment. Evaluation should address real issues, provide staff and stakeholders with reliable information to address challenges, and build on strengths and opportunities (Frey \& Seitz, 2009). Evaluation should invite multiple perspectives and involve a representation of people who care and benefit from the program. Likewise, evaluators and implementers must be adaptable by working together to respond to the needs of program stakeholders. Evaluation should build the skills, knowledge, perspectives of individuals to selfreflect, dialogue, and act based on data and knowledge.

Evaluative thinking is a process of collecting and analyzing data to convey a strategy, initiative, program, policy, or organization (Kellogg, 2017). Evaluative thinking is a systematic process that is valuable and necessary in a culture of innovation. Such a process involves identifying assumptions about what is perceived to work, what does not work, and why; posing thoughtful questions about what changes after program implementation; pursuing deeper understanding through reflection and dialogue; communicating the learned experience without underestimation or exaggeration; and making informed decisions in preparation for action (Kellogg, 2017). 


\section{Confidentiality in Research}

Confidentiality and non-disclosure agreements enact confidentiality obligations on parties receiving material data from disclosing parties that consider data or material to be confidential. Preparing an appropriate agreement requires consideration of some key issues. The evaluator should identify which data meet confidentiality standards. There may be limitations on what data is deemed confidential, such as data already known to those surveyed. No matter whether receiving or disclosing data, confidentiality measures require consideration. The duration for keeping the data confidential is also needed. Also important is explaining the purpose for disclosure, i.e., confidential data shared with another party for a specific purpose. Most important, the agreement should indicate the purpose of the survey.

The primary reasons why researchers prefer survey data are that surveys disclose responses from respondents providing more context to the evaluation or a study. In an unbiased survey condition, the researcher finds what inspires survey respondents and what is imperative to them, such as their feelings, comments, and input. An unbiased survey condition is one that best suits the well-being of the survey respondent. Respondents should give transparent criticism in an anonymous survey technique. For example, online or paper surveys are more private than vis-à-vis survey meetings or phone surveys. Survey respondents should have a chance to reflect on imperative key themes. Conducting surveys is an unbiased way to receive authentic responses. Gathering impartial survey information is necessary.

Qualitative research is utilized in research to promote a thoroughly efficient way to yield significant and useful outcomes (Moser \& Korstjens, 2018). Authoritative qualitative analysts must provide analysis that has been conducted in an exacting, reliable, and thorough way by accurately chronicling, systematizing, and recording the strategies for analysis with enough detail to allow readers to decide if the procedure is reliable. Although there are various instances of conducting qualitative research, few refined strategies are accessible to researchers for conducting a thorough and applicable topical analysis (Moser \& Korstjens, 2018). A means of conducting a topical analysis can be made by an auditable trail, providing interpretation, and presenting the data. In this way, the outcome of research contributes intentionally by systematizing and providing verification of the analysis (Makowski, 2021; Yang et al., 2020).

Execution reports advance evaluation research outcomes. Status reports recognize where a task is in its present state to ascertain research changes. Reports estimate a schedule at finish, schedule to finish, and planned execution status providing researchers and instructors a context to the evaluation plan. Eventually, special case reports depend on challenges, issues, and opportunities (Stufflebeam, 2003). The distinct kinds of execution reports are helpful to gauge where the researcher is during the process. These reports contain data utilized for task administration and execution. Likewise, there are four types of evaluation reports: general execution reports, status reports, research reports, and special case reports (Stufflebeam, 2003).

Regarding reporting evaluation data, Thomas (2006) indicated that a general inductive approach for analysis of qualitative evaluation data is to condense raw textual data into a summary format; establish demonstrative connections between the evaluation or research goals and the summary findings constructed from the raw data, and build a framework of the uncovered experiences or processes revealed in the raw data. The general inductive methodology gives an effectively utilized and efficient arrangement of systems for examining subjective information that can deliver substantial discoveries. Even though the general inductive methodology is not as impactful as some other expository procedures for hypothesis or model improvement, it provides a basic, direct methodology for inferring data regarding logical assessment questions. Many evaluators discover that utilizing a general inductive methodology is less confusing than utilizing other ways to work with subjective analysis.

\section{Recommendations}

The scientific method, the literature review, and ethics are principal points of interest, which lie in the potential advantage each offers to research publications or grant opportunities of both the researcher and an institution. As a result, the advantages of adhering to the research process facilitate ascendency in 
the professions and show a commitment to research agency as a multidimensional phenomenon (Jääskelä et al., 2021). Further, literature reviews offer a structured approach that researchers can fine-tune based on current information as the study evolves. Along these lines, researchers are responsible for developing and improving researcher agency as they participate in research projects (Yang et al., 2020).

\section{Conclusion}

Indeed, literature review development allows researchers to utilize many research tools and information to understand data and content implementation. Tools for literature review construction exist as classified primary or secondary source related. Well-managed literature review development involves building a structure for the study and assessing content for validity (Rigler et al., 2021). Literature review development of this nature occurs to ascertain studies that most align with the purpose of the research. Last, poor-quality searches yield unsubstantiated data and information. For instance, there are outputs but no valid and useful inputs. Finally, by incorporating an ethical and strategic approach to literature reviews, researcher agency is vastly improved.

\section{Competing Interests}

The author declares there is no conflict of interest.

\section{How to Cite this Article:}

A. El-Amin, “An Examination of Research Agency and its Practical Applications”, Extsv. Rev., vol. 1, no. 1, pp. 7-15, Dec. 2021.

\section{References}

Al-Ali, A. A., Singh, S. K., Al-Nahyan, M., \& Sohal, A. S. (2017). Change management through leadership: The mediating role of organizational culture. International Journal of Organizational Analysis.

Amiot, C. E., Sukhanova, K., \& Bastian, B. (2020). Social identification with animals: Unpacking our psychological connection with other animals. Journal of personality and social psychology, 118(5), 991.

Arthur, J. (Ed.). (2012). Research methods and methodologies in education. Sage publications.

Belmont Report. (1979). The Belmont Report: Ethical principles and guidelines for the protection of human subjects of research. http://www.hhs.gov/ohrp/humansubjects/guidance/belmont.html

Creswell, J. W., \& Creswell, J. D. (2017). Research design: Qualitative, quantitative, and mixed methods approach. Sage publications.

Cypress, B. S. (2017). Rigor or reliability and validity in qualitative research: Perspectives, strategies, reconceptualization, and recommendations. Dimensions of Critical Care Nursing, 36(4), 253-263.

Eisner, E. W. (2017). The enlightened eye: Qualitative inquiry and the enhancement of educational practice. Teachers College Press.

Ferreira, R., Ebersöhn, L., \& Mbongwe, B. B. (2015). Power-sharing partnerships: teachers' experiences of participatory methodology. Progress in community health partnerships: Research, Education, and Action, 9(1), 7-16.

Frye, A. W., \& Hemmer, P. A. (2012). Program evaluation models and related theories: AMEE guide no. 67. Medical teacher, 34(5), e288e299.

Frey, A., \& Seitz, N. N. (2009). Multidimensional adaptive testing in educational and psychological measurement: Current state and future challenges. Studies in Educational Evaluation, 35(2-3), 89-94.

Granic, A., \& Cukusic, M. (2011). Usability testing and expert inspections complemented by educational evaluation: A case study of an elearning platform. Journal of Educational Technology \& Society, 14(2), 107.

Haig, B. D. (2018). An abductive theory of scientific method. In Method Matters in Psychology (pp. 35-64). Springer, Cham.

Howe, A. (2019). Why Kant animals have rights?. Journal of Animal Ethics, 9(2), 137-142.

Jääskelä, P., Heilala, V., Kärkkäinen, T., \& Häkkinen, P. (2021). Student agency analytics: Learning analytics as a tool for analyzing student agency in higher education. Behaviour \& Information Technology, 40(8), 790-808. https://doi.org/10.1080/0144929X.2020.1725130

Jones, N. \& Preskill, H. (2009). A practical guide for engaging stakeholders in developing evaluation questions. http://www.pointk.org/resources/files/rwj.stakeholders.final.1.pdf

Knight, P. (2012). Assessment for learning in higher education. Routledge.

Kroll, A., \& Moynihan, D. P. (2018). The design and practice of integrating evidence: connecting performance management with program evaluation. Public administration Review, 78(2), 183-194.

McLeod, S. (2017). The Milgram shock experiment. https://www.simplypsychology.org/milgram.html

Moser, A., \& Korstjens, I. (2018). Series: Practical guidance to qualitative research. Part 3: Sampling, data collection, and analysis. European Journal of General Practice, 24(1), 9-18.

Okoroma, F. N. (2011). Towards effective management of grey literature for higher education, research, and national development. Library Review.

Makowski, P. (2021). Practical intentionality: Injecting analytical theory of agency into organizational research. In Academy of Management Proceedings (Vol. 2021, No. 1, p. 10880). Academy of Management. https://doi.org/10.5465/AMBPP.2021.144 
Abeni El-Amin, Extsv. Rev.; Vol. 1, Issue 1, pp: 7-15, 2021

Nguyen, H., \& Kleiner, B. H. (2003). The effective management of mergers. Leadership \& Organization Development Journal, 24(8), 447454.

Peterson, J. (2019). An analysis of academic dishonesty in online classes. Mid-Western Educational Researcher, 31(1).

Preskill, H., \& Catsambas, T. T. (2006). Reframing evaluation through appreciative inquiry. Sage Publications.

Privitera, G. (2019). Research methods for the behavioral sciences (3rd ed.). Sage.

Rigler Jr, K. L., Anastasia, C. M., El-Amin, A., \& Throne, R. (2021). Scholarly voice and academic identity: A systematic review of doctoral student agency. Handbook of Research on Developing Students' Scholarly Dispositions in Higher Education, 63-89.

Schildkamp, K., \& Visscher, A. (2009). Factors influencing the utilization of a school self-evaluation instrument. Studies in Educational Evaluation, 35(4), 150-159.

Sivarajah, U., Kamal, M. M., Irani, Z., \& Weerakkody, V. (2017). Critical analysis of big data challenges and analytical methods. Journal of Business Research, 70, 263-286.

Somers, M. A., Zhu, P., Jacob, R., \& Bloom, H. (2013). The validity and precision of the comparative interrupted time series design and the difference-in-difference design in educational evaluation. MDRC.

Sprumont, D. (2020). Research Ethics Regulation. Ethical Research: The Declaration of Helsinki, and the Past, Present, and Future of Human Experimentation, 241.

Stewart, C. (2014). Transforming professional development to professional learning. Journal of Adult Education, 43(1), 28-33.

Strijbos, J. W. (2011). Assessment of (computer-supported) collaborative learning. IEEE transactions on learning technologies, 4(1), 59-73.

Stufflebeam, D. L. (2003). The CIPP model for evaluation. In International handbook of educational evaluation (pp. 31-62). Springer, Dordrecht.

Stufflebeam, D. L. (2007). CIPP evaluation model checklist. https://wmich.edu/sites/default/files/attachments/u350/2014/cippchecklist_mar07.pdf

Tarzian, A. J. (2017). Ethicist. Encyclopedia of Global Bioethics: 1-9.

Thomas, D. R. (2006). A general inductive approach for analyzing qualitative evaluation data. American Journal of evaluation, 27(2), 237246.

Turner, S. F., Cardinal, L. B., \& Burton, R. M. (2017). Research design for mixed methods: A triangulation-based framework and roadmap. Organizational Research Methods, 20(2), 243-267.

Tuckman, B. W., \& Harper, B. E. (2012). Conducting educational research. Rowman \& Littlefield Publishers.

William, D. (2011). What is assessment for learning? Studies in educational evaluation, 37(1), 3-14.

W.K. Kellogg Foundation (Kellogg). (2017). The step-by-step guide to evaluation how to become savvy evaluation consumers. https://www.wkkf.org/resource-directory/resource/2010/w-k-kellogg-foundation-evaluation-handbook

Yang, W., Li, Y., Zhou, W., \& Li, H. (2020). Learning to design research: Students' agency and experiences in a Master of Education program in Hong Kong. ECNU Review of Education, 3(2), 291-309. https://doi.org/10.1177/2096531120917163

Zikmund, W. G., Babin, B. J., Carr, J. C., \& Griffin, M. (2013). Business research methods (9th ed.). Thomson/South-Western.

Publish your research article in AIJR journals-

- $\quad$ Online Submission and Tracking

- $\quad$ Peer-Reviewed

- Rapid decision

- Immediate Publication after acceptance

- $\quad$ Articles freely available online

- Retain full copyright of your article.

Submit your article at journals.aijr.org
Publish your books with AIJR publisher-

- Publish with ISBN and DOI.

- Publish Thesis/Dissertation as Monograph.

- Publish Book Monograph.

- $\quad$ Publish Edited Volume/ Book.

- $\quad$ Publish Conference Proceedings

Submit your manuscript at books.aijr.org 